\title{
Det svenska fångtalets utveckling 1910-2010
}

\author{
Af Hanns von Hofer ${ }^{l}$
}

\begin{abstract}
This article is a summary of a speech given at the $100^{\text {th }}$ anniversary of the Swedish Association of Criminalists (Svenska Kriminalistföreningen). The historical development of the Swedish prison population from its beginning until today is briefly described. The author argues that a considerable proportion of the increase in the Swedish prison population during the last 50 years is due to repressive policies concerning narcotic drugs. These policies not only increase the prison population, but also cause hundreds of deaths each year. Less repressive drug policies would therefore both decrease the number of prisoners and save lives.
\end{abstract}

\section{Ärade församling!}

I sina memoarer skriver Torsten Eriksson, chefen för svensk kriminalvård under åren 1960-1970, om Karl Johan Schlyter, en av de stora namnen i svensk kriminalpolitik:

»Han [Schlyter] hade lagt fram två reformförslag, ett redan 1932 och ett annat 1934, och han hade haft den stora smaklösheten att presentera det senare programmet [...] vid ett vanligt folkmöte i Stockholms Auditorium, i stället för i Kriminalistföreningen eller Fångvårdssällskapet, de organisationer där den verkliga sakkunskapen var samlad.« (Eriksson, 1977:49)

Det senare programmet gick under mottot »Att avfolka fängelserna« och syftade till att befria fängelserna från ungdomar, psykiskt störda personer och s.k. förvandlingsfångar, dvs. personer som inte kunde betala böter och därför dömdes till ett kort fängelsestraff.

Sommaren 1974 var det dags igen, när dåvarande justitieminister Lennart Geijer höll ett anförande inför finska och svenska frivårdstjänstemän. Geijer sa bl.a.: »Vi har för närvarande cirka 3500 fångar i de svenska fängelserna. Antalet har sedan fyra-fem år tillbaka stadigt minskat och det finns ingenting som tyder på att trenden skall rubbas. Jag har tidigare uttalat den förhoppningen att vi före 1970-

* Title in English: Swedish Incarceration Rates, 1910-2010. 
talets slut skulle vara nere i 3000 intagna i fängelserna. Det ser nu ut som om även den prognosen är tilltagen i överkant.« (Geijer, 1974:1-2)

Både Schlyter och Geijer har gjort visst avtryck i fångstatistiken, men i det stora hela var det andra och mäktigare krafter som bestämde det svenska fångtalets utveckling under 1900-talet.

Sett $\mathrm{i}$ ett längre historiskt perspektiv kan vi konstatera att fängelserna inte är någon speciellt gammal institution. Visserligen har det funnits förlöpare långt tillbaka i tiden, men fängelsets genombrott som straffinstitution inträffade under första hälften av 1800-talet, där fängelse ersatte döds- och kroppsstraff och där inspärrning användes i stor skala för att komma till rätta med den utbredda undersysselsättningen innan industrialiseringen tog fart efter 1870 (»tvångsarbetsfångar «). Fr.o.m. 1840-talet sattes ett storstilat fängelsebyggnadsprogram i verket samtidigt som en ny strafflagstiftning kom på plats under 1850- och början av 1860-talen. Beläggningen på fängelserna började sjunka igen, vilket är en av de stora kriminalpolitiska bedrifter som åstadkoms under andra hälften av 1800talet. Men det var inte bara fångbeläggningen som minskade utan också antalet dödsdöma och avrättade samt antalet livstidsfångar.

Utvecklingen under andra hälften av 1800-talet är mycket lärorik ur kriminalpolitisk synvinkel, eftersom den visar att två mycket symbolladdade påföljder dödsstraff och livstidfängelse - i praktiken utmönstras ur den svenska straffarsenalen. När det gäller dödsstraffet ägde den sista avrättningen rum 1910 och åren 1970, 1972, 1973 och 1975 dömdes ingen person till livstids fängelse. Visserligen ökade antalet livstidsdömda igen mot slutet av 1900-talet, men i ett långt historiskt perspektiv framstår det ändå som ovedersägligt: påföljdssystemets utformning är inte gjuten i betong - grundläggande förändringar är möjliga. Det går att åstadkomma det otänkbara. Man måste arbeta för det.

Det otänkbara idag är ett straffsystem som skulle kunna undvara frihetsstraffet eller åtminstone starkt begränsa dess användning. En av fängelsernas stora hemligheter är ju att det inom en historiskt mycket kort period lyckades bli symbolen för straffet i sig och att det fick spridning över hela världen - trots att fängelsestraffets effektivitet inte ligger i öppen dager. Tvärtom. De allra flesta kan nog enas om

1. att fängelserna är en omvittnat dyr strafform;

2. att fängelserna inte förhindrar återfall bättre än andra straffsanktioner och att allmänpreventiva marginaleffekter är notoriskt svåra att påvisa;

3. att fängelserna är orättvisa även om den enskilda fängelsedomen för det mesta framstår som rättvis. Typfången är socialt marginaliserad. 
Icke desto mindre har den svenska fängelsepopulationen mellan 1910 och 2010 ökat från c:a 3000 till c:a 7000 fångar (eller från omkring 55 till 75 făngar per 100000 invånare). Vilka är då de som dömdes till fängelse 1910 och 2010? Tabell 1 beskriver de brottstyper som ledde till inspärrning för 100 år sedan och idag.

Tabell 1. Nykomna fångar, 1910 och 2010

(BiSOS 1910 och Kriminalstatistik 2010).

\begin{tabular}{lrr} 
& \multicolumn{1}{c}{1910} & \multicolumn{1}{c}{2010} \\
\cline { 2 - 3 } Stöldbrott & $45 \%$ & $14 \%$ \\
Våldsbrott & $19 \%$ & $20 \%$ \\
Bedrägeribrott & $4 \%$ & $5 \%$ \\
Sexualbrott & $2 \%$ & $3 \%$ \\
Rån & $0 \%$ & $5 \%$ \\
Övriga brott & $29 \%$ & $53 \%$ \\
Summa & $100 \%$ & $100 \%$ \\
& $(\mathrm{n}=2896)$ & $(\mathrm{n}=9679)$
\end{tabular}

Utan att fördjupa oss i detaljer kan vi konstatera två viktiga förändringar. Stöldbrott som intagningsgrund har avtagit, medan en ny brottstyp har tillkommit. Den döljer sig bakom beteckningen »Övriga brott« och avser narkotikabrottsligheten. Enligt den senast tillgängliga sammanställningen hade år 2009 inte mindre än tjugo procent av samtliga lagföringar (c:a 140000 stycken) direkt med illegal hantering av narkotika att göra. Narkotika gjordes till ett straffrättsligt problem i slutet av 1960-talet (Lenke, 2007; Victor, 2007) och sedan dess har antalet fängelseår som dömts ut för narkotikabrott ökat mycket kraftigt: från i princip noll fängelseår före 1968 till över 3000 fängelseår i slutet av perioden.

Utvecklingen innebär att antalet platser som upptas av făngar dömda för narkotikabrott (inkl. Lag om straff för smuggling) har ökat från 46 (år 1969) till 1 692 (år 2010) eller från 1 procent till 31 procent av samtliga intagna.

Man kan då fråga sig om narkotikapolitikens starka inriktning på straffrättslig repression har varit framgångsrik. Olyckligtvis saknas den stora utvärderingen av svensk narkotikapolitik (Blomqvist \& Olsson, 2011), men oavsett möjliga vinster har den svenska (och nordiska) narkotikapolitiken kostat många människoliv. Detta går att utläsa ur dödsorsaksstatistiken. ${ }^{2}$

År 2010 registrerades 420 narkotikarelaterade dödsfall som underliggande eller bidragande orsak: 100 kvinnor och 320 män. Som en jämförelse kan nämnas att samma år mördades eller dräptes 26 kvinnor och 62 män. Men döda narkoti- 
kaberoende, inte ens kvinnliga, föranleder någon »haverikommission «. ${ }^{3}$ Kan vi förstå talens innebörd?

Antal narkotikarelaterade dödsfall som underliggande eller bidragande orsak, 2010, samt mördade och dräpta personer [mörkare fält], 2010. Källa: Dödsorsaker 2010.

»Avlyssnad horisont. De vill säga något, de döda.

De röker men äter inte, de andas inte men har rösten kvar.«

Tomas Tranströmer, Djupt i Europa (1989 [2011:342])

\begin{tabular}{|c|c|c|c|c|c|c|c|c|c|c|c|c|c|c|c|c|c|c|c|c|}
\hline$\dagger$ & $\dagger$ & $\dagger$ & $\dagger$ & $\dagger$ & $\dagger$ & $\dagger$ & $\dagger$ & $\dagger$ & $\dagger$ & $\dagger$ & $\dagger$ & $\dagger$ & $\dagger$ & $\dagger$ & $\dagger$ & $\dagger$ & $\dagger$ & $\dagger$ & $\dagger$ & $\dagger$ \\
\hline$\dagger$ & $\dagger$ & $\dagger$ & 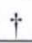 & $i$ & $\dagger$ & & & & $\dagger$ & & & & $\dagger$ & & & $\dagger$ & $\dagger$ & $\dagger$ & $\dagger$ & $\dagger$ \\
\hline$\dagger$ & $\dagger$ & $\dagger$ & $\dagger$ & $\dagger$ & $\dagger$ & $\dagger$ & 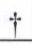 & $\dagger$ & $\dagger$ & $\dagger$ & 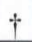 & $\dagger$ & $\dagger$ & $\dagger$ & & $\dagger$ & $\dagger$ & $\dagger$ & $\dagger$ & $\dagger$ \\
\hline$\dagger$ & $\dagger$ & $\dagger$ & $\dagger$ & $\dagger$ & $\dagger$ & $\triangle$ & $\dagger$ & $\dagger$ & $\dagger$ & $\therefore$ & $\dagger$ & $\dagger$ & $\dagger$ & 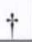 & . & $\dagger$ & $\dagger$ & $\dagger$ & $\dagger$ & $\dagger$ \\
\hline$\dagger$ & $\dagger$ & $\dagger$ & $\dagger$ & $\dagger$ & $\dagger$ & $t$ & $\rightarrow$ & $\dagger$ & $\dagger$ & 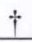 & $\dagger$ & $\dagger$ & $\dagger$ & $\dagger$ & $\dagger$ & $\dagger$ & $\dagger$ & $\dagger$ & $\dagger$ & $\dagger$ \\
\hline$\dagger$ & $\dagger$ & $\dagger$ & $\dagger$ & $\dagger$ & $\dagger$ & $\dagger$ & + & $\dagger$ & $\dagger$ & $\dagger$ & $\dagger$ & $\dagger$ & $\dagger$ & $\dagger$ & $\dagger$ & $\dagger$ & $\dagger$ & $\dagger$ & $\dagger$ & $\dagger$ \\
\hline$\dagger$ & $\dagger$ & $\dagger$ & $\dagger$ & $\dagger$ & $\dagger$ & $\dagger$ & + & $\dagger$ & $\dagger$ & $\rightarrow$ & + & + & $\dagger$ & $\dagger$ & 1 & $\dagger$ & $\dagger$ & $\dagger$ & $\dagger$ & $\dagger$ \\
\hline$\dagger$ & $\dagger$ & $\dagger$ & $\dagger$ & $\dagger$ & $\dagger$ & $\dagger$ & $\dagger$ & $\dagger$ & $\dagger$ & $\dagger$ & $\dagger$ & $\dagger$ & $\dagger$ & $\dagger$ & $\dagger$ & $\dagger$ & $\dagger$ & $\dagger$ & $\dagger$ & $\dagger$ \\
\hline$\dagger$ & $\dagger$ & $\dagger$ & $\dagger$ & $\dagger$ & $\dagger$ & $\dagger$ & $\dagger$ & $\dagger$ & $\dagger$ & 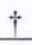 & + & $\dagger$ & $\dagger$ & + & $\leftarrow$ & $\dagger$ & $\dagger$ & $\dagger$ & $\dagger$ & $\dagger$ \\
\hline$\dagger$ & $\dagger$ & $\dagger$ & $\dagger$ & $\dagger$ & $\dagger$ & $\dagger$ & $\dagger$ & $\dagger$ & $\dagger$ & $\dagger$ & 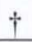 & $\dagger$ & $\dagger$ & $\dagger$ & 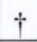 & $\dagger$ & $\dagger$ & $\dagger$ & $\dagger$ & $\dagger$ \\
\hline$\dagger$ & $\dagger$ & $\dagger$ & $\dagger$ & $\dagger$ & $\dagger$ & $\dagger$ & $\dagger$ & $\dagger$ & $\dagger$ & $\dagger$ & 1 & $\dagger$ & $\dagger$ & $\dagger$ & $\dagger$ & $\dagger$ & $\dagger$ & $\dagger$ & $\dagger$ & $\dagger$ \\
\hline$\dagger$ & $\dagger$ & $\dagger$ & $\dagger$ & $\dagger$ & $\dagger$ & $\dagger$ & $\dagger$ & $\dagger$ & $\dagger$ & $\dagger$ & $\dagger$ & $\dagger$ & $\dagger$ & $\dagger$ & $\dagger$ & $\dagger$ & $\dagger$ & $\dagger$ & $\dagger$ & $\dagger$ \\
\hline$\dagger$ & $\dagger$ & $\dagger$ & $\dagger$ & $\dagger$ & $\dagger$ & $\dagger$ & $\dagger$ & $\dagger$ & $\dagger$ & $\dagger$ & $\dagger$ & $\dagger$ & $\dagger$ & $\dagger$ & $\dagger$ & $\dagger$ & $\dagger$ & $\dagger$ & $\dagger$ & $\dagger$ \\
\hline$\doteq$ & $\dagger$ & $\dagger$ & $\dagger$ & $\dagger$ & $\dagger$ & $\dagger$ & 1 & 1 & $\dagger$ & 1 & 1 & $T$ & $\dagger$ & 1 & 1 & $\dagger$ & $\dagger$ & 1 & $\dagger$ & $\dagger$ \\
\hline$\dagger$ & $\dagger$ & $\dagger$ & $\dagger$ & $\dagger$ & $\dagger$ & $\dagger$ & 1 & 1 & $\dagger$ & 1 & 1 & 1 & $\dagger$ & 1 & 1 & $\dagger$ & $\dagger$ & $\dagger$ & $\dagger$ & $\dagger$ \\
\hline$\dagger$ & $\dagger$ & $\dagger$ & $\dagger$ & $\dagger$ & $\dagger$ & $\dagger$ & $\dagger$ & 1 & $\dagger$ & 1 & 1 & 1 & $\dagger$ & $\dagger$ & 1 & $\dagger$ & $\dagger$ & $\dagger$ & $\dagger$ & $\dagger$ \\
\hline$\dagger$ & $\dagger$ & $\dagger$ & $\dagger$ & $\dagger$ & $\dagger$ & $\dagger$ & 4 & $\star$ & $\dagger$ & 1 & 1 & 1 & $\dagger$ & $\dagger$ & 1 & $\dagger$ & $\dagger$ & $\dagger$ & $\dagger$ & $\dagger$ \\
\hline$\dagger$ & $\dagger$ & $\dagger$ & $\dagger$ & $\dagger$ & $\dagger$ & $\dagger$ & $\dagger$ & $\dagger$ & $\dagger$ & $\dagger$ & $\dagger$ & $\dagger$ & $\dagger$ & $\dagger$ & $\dagger$ & $\dagger$ & $\dagger$ & $\dagger$ & $\dagger$ & $\dagger$ \\
\hline$\dagger$ & $\dagger$ & $\dagger$ & $\dagger$ & $\dagger$ & $\doteqdot$ & $\dagger$ & $\dagger$ & $\dagger$ & $\dagger$ & $\dagger$ & $\dagger$ & $\dagger$ & $\dagger$ & $\dagger$ & $\dagger$ & $\dagger$ & $\dagger$ & $\dagger$ & $\dagger$ & $\dagger$ \\
\hline$\dagger$ & $\dagger$ & $\dagger$ & $\dagger$ & $\dagger$ & $\dagger$ & $\dagger$ & $\dagger$ & $\dagger$ & $\dagger$ & $i$ & $\dagger$ & $\dagger$ & $\dagger$ & $\dagger$ & $\dagger$ & $\dagger$ & $\dagger$ & $\dagger$ & $\dagger$ & $\dagger$ \\
\hline
\end{tabular}


Vad skulle de många döda drogberoende kunna vilja säga oss? Kanske det här:

- Överge målet om ett narkotikafritt samhälle till förmån av ett samhälle där drogberoende inte behöver dö i förtid. ${ }^{4}$

- Nedkriminalisera på narkotikaområdet, vilket minskar antalet fångar på fängelserna.

Kanske de ropar: »Avfolka fängelserna genom att avgifta straffrätten!«

Figur 1. Kvarvarande fångar $i$ svenska fängelser, 1750-2010. 5-års medeltal, per 100000 invånare. Källa: von Hofer (2010).

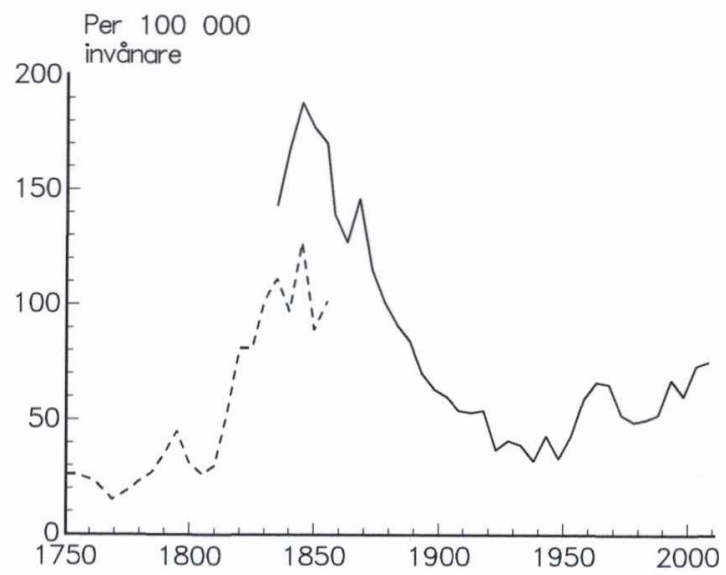


Figur 2. Antal avrättade [vänster], 1750-1920, och nykomna livstidsfångar [höger], 1858-2010. Källa: von Hofer (2010).

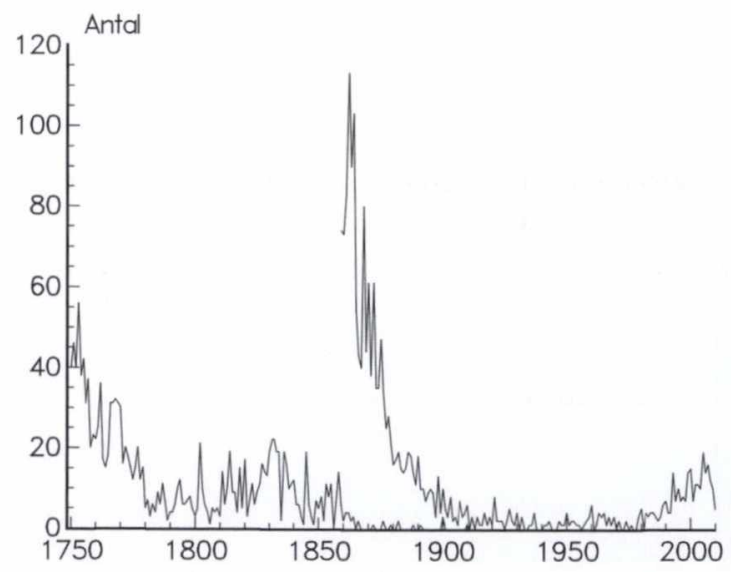

Figur 3. Summa fängelseår för brott mot narkotikastrafflagen och varusmugglingslagen/Lag om straff för smuggling, 1973-2010.

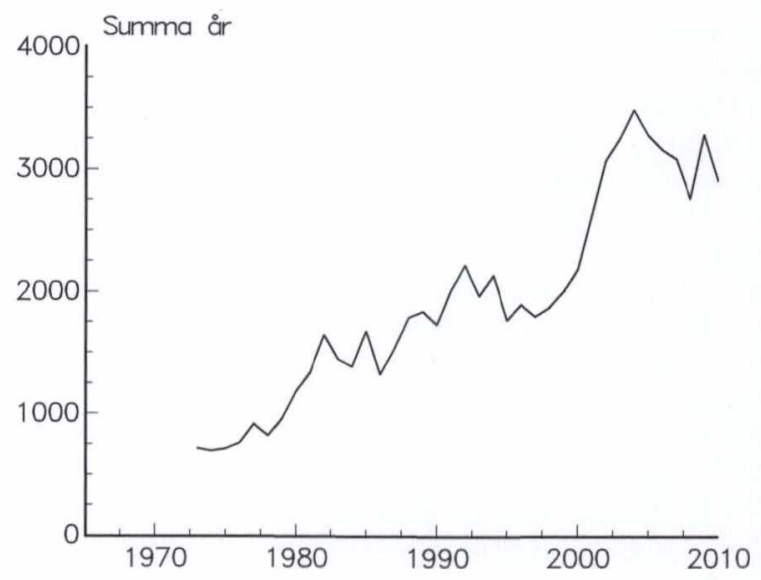




\section{Figur 4. Antal narkotikarelaterade dödsfall som underliggande eller bidragande orsak, 1969-2010} (CAN 2010, Tab. 89 och Dödsorsaker 2010, Tab. 9).

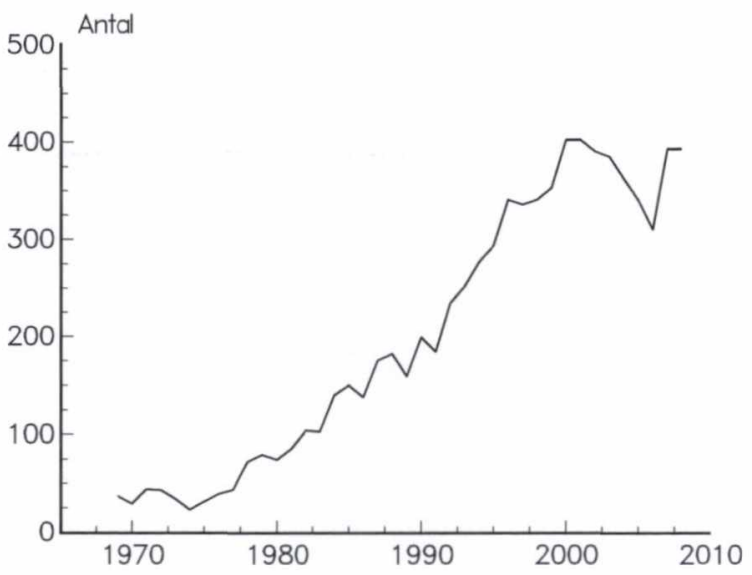

\section{Noter}

1. Hanns von Hofer är professor emeritus i kriminologi vid Stockholms universitet. Hans forskning är inriktad på brottsutveckling och kriminalpolitik, särskilt i historiskt och europeiskt perspektiv.

2. Jfr. European Monitoring Centre for Drugs and Drugs Addiction (Årsrapport 201 1): »Treatment can significantly reduce the mortality risk of drug users, although risks related to drug tolerance arise when entering or leaving treatment. Studies show that the risk of druginduced death on relapse after treatment or in the weeks after release from prison is substantially elevated.«

3. Detta anspelar på att sedan den 1 januari 2012 granskar en ny s.k. haverikommission alla fall där en kvinna (eller man) dödas av en närstående person (se 2011/12:SoU3 Utredningar avseende vissa dödsfall). Man räknar med att det genomsnittligt handlar om 16-17 kvinnor årligen som dödas av en närstående man.

4. Jfr. Regeringsformen 1 kap. 2 §st. 2: »Den enskildes personliga, ekonomiska och kulturella välfärd skall vara grundläggande mål för den offentliga verksamheten. Det skall särskilt åligga det allmänna att trygga rätten till arbete, bostad och utbildning samt att verka för social omsorg och trygghet och för en god levnadsmiljö.« (Min kursivering) 


\section{Referenser}

2011/12:SoU3. Utredningar avseende vissa dödsfall.

BiSOS. G) Fångvården. Fångvårds-Styrelsens underdåniga berättelse för år 1910. Stockholm: Norstedts.

Blomqvist, Jan \& Olsson, Börje (2011). Narkotika. Om problem och politik. Stockholm: Norstedts juridik.

CAN (2010). Drogutvecklingen i Sverige 2010. Rapport nr 125. Stockholm: Centralförbundet för alkohol- och narkotikaupplysning.

Dödsorsaker 2010 (2011). Socialstyrelsen. Sveriges officiella statistik. Hälso- och sjukvård. Stockholm.

European Monitoring Centre for Drugs and Drug Addiction (2011). 2011 Annual report-online version. http://www.emcdda.europa.eu/online/annual-report/2011 (2012-02-27).

Eriksson, Torsten (1977). Politik och kriminalpolitik. Stockholm: Norstedts.

Geijer, Lennart (1974). Anförande vid svenska och finska socialtjänstemannaförbundens studiedagar. Stencil 1974-08-05. [Kan beställas från förf.]

von Hofer, Hanns (2011). Brott och straffi Sverige. Rapport 2011:3. Kriminologiska institutionen. Stockholm: Stockholms universitet.

Kriminalstatistik 2010. Kriminalstatistik 2010. Rapport 2011:11. Stockholm: Brottsförebyggande rådet.

Lenke, Leif (2007). »Kriminalpolitiken som partipolitiskt »högerprojekt« - en evig självklarhet? « I: Hanns von Hofer \& Anders Nilsson (red.), Brott $i$ välfärden. Om brottslighet, utsatthet och kriminalpolitik. Festskrift till Henrik Tham. Rapport 2007:1. Kriminologiska institutionen. Stockholm: Stockholms universitet.

Schlyter, Karl (1935). Avfolka fängelserna! Stockholm: Tiden. [Kan beställas från förf.]

Tranströmer, Tomas (2011). Samlade dikter 1954-1996.[Stockholm:] Bonnier Pocket.

Victor, Dag (2007). »Narkotikabrottslighetens gärningsmän och offer.« I: Hanns von Hofer \& Anders Nilsson (red.), Brott $i$ välfärden. Om brottslighet, utsatthet och kriminalpolitik. Festskrift till Henrik Tham. Rapport 2007:1. Kriminologiska institutionen. Stockholm: Stockholms universitet. 